\title{
Preventive Obligations: Some Introductory Comments
}

\author{
Eva Rieter ${ }^{1}$
}

Published online: 7 February 2022

(c) T.M.C. Asser Press 2022

\section{Introduction}

Better safe than sorry. In the face of pandemics and climate change the importance of this maxim requires no explanation. Much of international law is concerned with the responsibility for unlawful conduct and repairing damage after the fact. But international law has also developed substantive and procedural tools to prevent harm from being caused, both by state agents and by third parties such as companies. These tools include due diligence, precaution, prior consultation, early warning, interim measures, data gathering and monitoring, impact assessment and guarantees of nonrepetition. Below are four articles examining the content and effectiveness of these tools in the field of international human rights law. Preventive tools have also been defined and employed in other fields of international law, such as international environmental law, the law of the sea, international health law and the law of armed conflict. This journal would welcome further contributions discussing the merits of tools to prevent (irreparable) harm as they have been tried and tested in different areas of international law. It should be possible to draw further lessons and promote cross-fertilization.

The focus of the present issue is on the obligation to prevent harm resulting from structural violations of human rights law. Structural human rights violations are violations that are part of a pattern of similar violations and that appear to be based on systemic underlying problems. This introductory note contains some preliminary remarks on preventive obligations in the context of human rights, introduces the contributions in this issue, draws attention to recent expert-led documents that shed light on specific aspects of the preventive human rights obligations of states and concludes with benchmarks for meeting preventive human rights obligations.

Eva Rieter

eva.rieter@ru.nl

1 Research Centre for State and Law, Radboud University Nijmegen, Nijmegen, The Netherlands 


\section{Preliminary Remarks on Preventive Obligations}

The underlying principles needed to clarify preventive obligations are derived from treaty provisions and from the due diligence standard. Which primary rules oblige states to prevent specific violations that follow a pattern unequally impacting on certain groups? Does the unequal impact increase the responsibility for a breach of those rules, and/or add the right to equality to the assessment of preventive obligations, taking focused action to address structural causes? Would this be action to prevent further structural violations, or would this be preventing specific violations while taking into account that they are part of a pattern and have structural causes?

The preventive measures that states (or other duty bearers) are expected to take under international law can be seen as being based on the direct primary rule: the obligation to act in order to prevent harm caused by state agents or by third parties. Yet they can also be seen as a form of redress amounting to guarantees of non-repetition. Indeed, it may well be that such measures can be seen as being required based on both a primary rule and as a form of 'preventive redress'. Especially in the face of violations that can be explained by (a combination of) structural problems, it does not seem possible to distinguish measures of redress from measures of prevention. In the end it may come down to responsive action based on an awareness that the situation must be changed in order to prevent such further violations, independent of the distinction between primary and secondary rules.

Structural violations could be redressed by proper investigation based on scientific data and interpretations thereof that aim to be unbiased, providing this information to interested groups and the public at large, drawing conclusions and following up by new policies and regulations.

An example could be: putting a stop to specific acts of corruption, ${ }^{1}$ because these in turn lead to other human rights violations of a structural nature. Or it could be: taking action to protect those who combat corruption from resulting death threats, explicitly stressing the importance of their work and enabling them to continue it. ${ }^{2}$ This means responding to systemic violations, whereby guarantees of non-repetition are explicitly preventive. Moreover, seeking truth and justice can also be seen as helping to safeguard against recurrence.

One question is what happens when there is a failure to redress, and the claim that this is part of a pattern based on underlying structural problems is not taken into account. For instance: a specific legislation or regulation was not (consciously) developed with a certain 'model citizen' in mind, or instead, a certain 'model suspect', but there are (now) indications that this legislation ignores the rights and interests of overlooked groups or has a disproportionate impact on marginalised groups. When public officials take measures denying this without investigation, or take measures that even exacerbate marginalisation, or when they announce investigations that are in fact not independent, this may come down to a failure to take

\footnotetext{
1 See e.g. Boersma (2012), Wouters et al. (2013), Rose (2015), Figueiredo (2017), and, focussing on preventive obligations: Peters (2018), pp. 1251-1287.

2 See e.g. IAComHR precautionary measures decision of 12 October 2021, Resolution No. 84/21, PM 845-21-Ligia del Carmen Ramos Zúñiga, Honduras.
} 
measures enhancing truth and reconciliation or even acting to undermine truth and reconciliation and thereby undermining trust in public officials.

\section{The Contributions in This Issue}

The four articles that follow below focus on the standard of due diligence, illustrating its translation into a primary rule: the obligation to ensure human rights, under the duty to protect, as well as its use in the secondary rule on providing guarantees of non-repetition (or non-recurrence in human rights parlance).

In 1988, in its seminal Velásquez-Rodríguez judgment, the Inter-American Court of Human Rights applied due diligence in a context of a pattern of similar violations, in that case disappearances. ${ }^{3}$ The CEDAW Committee introduced the standard in 1992 when it discussed the relationship between discrimination and violence against women. It did not yet use the terms 'pattern', 'structural' or 'systemic'. Nevertheless, substantively its recommendations of positive measures to be taken to avoid recurrence, such as 'identify the nature and extent of attitudes, customs and practices that perpetuate violence against women', ${ }^{4}$ clearly relate to structural measures.

In her contribution 'Do Guarantees of Non-Recurrence Actually Help to Prevent Systemic Violations? Reflections on Measures Taken to Prevent Domestic Violence', Carla Ferstman discusses the case law of the CEDAW Committee, which 'played an important role in articulating states' due diligence obligations and identifying discriminatory practices which contribute to the perpetuation of violence', including its discussion on gender stereotypes. At the same time, she observes a lack of the specification of necessary measures to prevent recurrence and a lack of critical follow-up in some cases.

She also discusses important case law in the Inter-American human rights system including on specific actions that should be taken to address systemic failures. Notably, in the Inter-American system general measures that must be taken to address structural problems are specified by the Commission and Court as part of their (quasi-)judicial functions, and both bodies also report to the OAS about compliance and have therefore set up monitoring systems. This is where the system differs considerably from the European human rights system. The systems have several other things in common, such as their 'living instrument' approach, but also certain legislative endeavours. Ferstman refers to specific treaties addressing violence against women: the Convention of Belém do Pará and the Istanbul Convention, respectively. Ferstman observes that in both systems these treaties have helped increase attention to systemic issues. Indeed, her contribution discusses important case law showing the European Court's specification of the positive obligations to prevent domestic violence as well. Yet the ECtHR has so far not been forthcoming with judgments examining the structural nature of domestic violence. It is the

\footnotetext{
${ }^{3}$ IACtHR Case of Velásquez-Rodríguez v. Honduras, Judgment of 29 July 1988 (on due diligence, see paras. 79 and 172 and on the pattern, see para. 147).

4 CEDAW General Recommendation No. 19: Violence against Women, A/47/38, 1992, paras. 11 and 24(e).
} 
Committee of Ministers that specifies the guarantees of non-repetition that must be provided. Its monitoring of the states' action reports is limited, which may be related to the limited resource capacity of its Department on the Execution of Judgments. It helps, though, when domestic NGOs are actively following up judgments, with the assistance of the European Implementation Network. ${ }^{5}$ Thus, Ferstman identifies a mixed bag at the Council of Europe level: instances of a lack of monitoring by the Committee of Ministers, but also a deepening understanding by the Committee of Ministers of the need for a 'variety of multidisciplinary measures necessary to tackle the structural antecedent of domestic violence'.

Paulo de Tarso Lugon Arantes, in his article 'The Due Diligence Standard and the Prevention of Racism and Discrimination' proposes a 'more efficient' use of the due diligence standard in order to address structural discrimination. This includes in any case making use of disaggregated data, ${ }^{6}$ a monitoring mechanism and an application of the principle of substantive equality addressing also indirect and de facto forms of discrimination. By referring to relevant case law he argues that in order to be truly preventive the monitoring mechanism should identify the root causes of structural discrimination and identify the measures to be taken to address these causes, in a process that respects a strong voice for racialised groups, meaning political empowerment and not just social assistance. He refers to the obligation to enact legislation to prevent acts of racial discrimination; the obligation to produce disaggregated racial and ethnic data; and the obligation to monitor instances of racial discrimination. Referring to patterns of police brutality and racism, he argues that effective preventive measures include theoretical and practical training of state agents on stress levels, de-escalation and the quality of the knowledge obtained by them (including an awareness of their own biases and an awareness about the situation of racialised groups). In this light he points out that so-called 'colour-blind policies' do not achieve an effective prevention of racial discrimination.

He also points out that '(p)ublic participation in the decision-making processes of legislation and regulation is another component of due diligence'. The state's

\footnotetext{
5 https://www.einnetwork.org/. Accessed 3 December 2022.

6 He provides a range of relevant examples. See e.g. CERD, Guidelines for Reporting, UN Doc. CERD/C/2007/1; General Recommendation No. 32, stressing the need for accurate data, disaggregated by race, ethnicity and other grounds, with a gender perspective, in order to appraise the specific needs of temporary special measures, para. 17 and UN High Commissioner on Human Rights, 2021 report on police brutality and racism, UN Doc. A/HRC/47/53, para. 16. The European Commission against Intolerance and Racism (ECRI) has also stressed the need to process data more consistently, systematically and comprehensively, while at the same time rejecting the argument that in light of data protection disaggregated data cannot be provided. ECRI, General Policy Recommendation No. 15, on Combating Hate Speech, Adopted on 8 December 2015, CRI(2016)15, para. 3(d). See also ECRI, General Policy Recommendation No. 14, CRI(2012)48, 22 June 2012. De Tarso Lugon Arantes stresses that 'scholarly works have pointed out that there are conciliatory views between the production of equality data and the infringement of privacy rights', mentioning De Schutter and Ringelheim (2010) and Makkonen (2012). While CERD has pointed out the need for accurate data to appraise specific needs, it has also stressed that 'algorithmic profiling systems should be continuously monitored as to their discriminatory effects', General Recommendation No. 36 (2020) on preventing and combating racial profiling by law enforcement officials, CERD/C/GC/36, 17 December 2020, para. 60. See infra n. 15.
} 
obligation to provide information is related. ${ }^{7}$ Specifically in the context of indigenous (land) rights he also draws attention to the preventive standard of free, prior, and informed consent (FPIC). This was introduced by the UN Declaration on the Rights of Indigenous Peoples (Art. 11.2) and adopted in the Inter-American, ${ }^{8}$ African $^{9}$ and UN systems. ${ }^{10}$

It is not surprising that in the systems whose treaties include a right to culture, interim (or provisional) measures have also been used, sometimes to protect cultural survival, ${ }^{11}$ and sometimes to prevent indigenous communities against death threats and harassment. In such contexts it has been pointed out that the protective measures to be taken by the state have to respect the connection to the land of the peoples involved, as well as take into account their culture in other respects. ${ }^{12}$

Opeoluwa Badaru's article 'Due Diligence and International Cooperation to Ensure Food Justice in the Context of Land Grabbing' explores how the due diligence standard and the standards regarding international cooperation in the context of the right to food could contribute to preventing and addressing further food injustice. She draws attention to the widespread and systemic nature of violations of the right to food and argues that further violations cannot be prevented "without addressing the questions of power and inequality in how food is produced and consumed'. The large-scale land acquisitions, 'many of which are shrouded in secrecy

\footnotetext{
${ }^{7}$ Indeed, the Inter-American human rights system has contributed significantly to the discourse on the relation between democracy and access to information, see in particular IACtHR Claude Reyes et al. $v$. Chile, Judgment of 19 September 2006, and IACtHR, The Environment and Human Rights (State Obligations in Relation to the Environment in the Context of the Protection and guarantee of the Rights to Life and to Personal Integrity-Interpretation and Scope of Articles 4(1) and 5(1) of the American Convention on Human Rights). Advisory Opinion OC-23/17, 15 November 2017. See further e.g., the Escazú Agreement, Regional Agreement on Access to Information, Public Participation and Justice in Environmental Matters in Latin America and the Caribbean (4 March 2018), CTC-XXVII-18 and the Council of Europe's Aarhuus Convention on Access to Information, Public Participation in Decision-Making and Access to Justice in Environmental Matters 25 June 1998, entered into force 30 October 2001, and its monitoring mechanism; and the Troms $\varnothing$ Convention, the Council of Europe Convention on Access to Official Documents (CETS No. 205), entered into force on 1 December 2020. See also on the consultation of stakeholders, witnesses etc.: International Commission of Jurists, The Future of Accountability Mechanisms: Twenty Recommendations, December 2021, Recommendations 11-15.

${ }^{8}$ See e.g. IACtHR Yakye Axa Indigenous Community v. Paraguay, Judgment of 17 June 2005; Case of the Sawhoyamaxa Indigenous Community v. Paraguay, Merits, Judgment of 29 March 2006; Case of the Saramaka People v. Suriname, judgment of 28 November 2007; IACtHR Case of Kichwa Indigenous People of Sarayaku v. Ecuador, Judgment of 27 June 2012 (see esp. para. 166).

${ }^{9}$ AComHPR Centre for Minority Rights Development (Kenya) and Minority Rights Group International on behalf of Endorois Welfare Council v. Kenya (Endorois case), 276/03, paras. 296-297, as required by the right to development; ACtHPR in Ogiek v Kenya, Judgment of 26 May 2017 only found that the state had failed to conduct prior consultations, paras. 131 and 210; see also Muigua (2019).

${ }^{10}$ See e.g. Report of the Special Rapporteur on the rights of indigenous peoples, A/HRC/33/42, 11 August 2016; HRCtee, Concluding Observations on Finland, UN Doc. CCPR/C/FIN/CO/7, 2021, para. 43.

${ }^{11}$ For older examples see Rieter (2010), pp. 451-500.

${ }^{12}$ For a recent example see the IAComHR precautionary measures of 23 April 2021 for the state to protect the safety of indigenous families in twelve communities through culturally relevant security measures in their communities and during their displacements and investigation of threats and attacks by third parties, in order to prevent recurrence. Resolution No. 35/21, PM 284-18-Tsotsil indigenous families from twelve communities in the municipality of Aldama, Chiapas, Mexico.
} 
and a lack of stakeholder consultation', have resulted in the displacement of indigenous inhabitants and have decreased the access to land and water resources. In her article she zooms in on 'the systemic problems of land grabbing and the production of biofuels at the cost of food for domestic consumption'. The due diligence standard, she posits, applies as a standard to examine a state's efforts to 'ensure food justice' also in this context.

States must take the necessary diligent steps to prevent harm by third parties (both persons and non-state entities) over which they can exercise control. In its General Comment 31 the UN Human Rights Committee stressed that the state must 'exercise due diligence to prevent, punish, investigate or redress the harm caused by such acts by private persons or entities'. ${ }^{13}$ In the context of food justice, the primary obligation of the state is its duty to protect the right to food and in this it must display due diligence. This is 'a duty to act in protection of a substantive right'. Due diligence is an obligation of conduct, not of result, and a reasonability criterion is applied in the assessment of the conduct. The state has to put in place legislation and policies 'to prevent private persons and non-state entities from acquiring large parcels of land for the purposes of biofuel production or food exports, particularly where such acquisitions will negatively impact the right to food of people living in the communities where these lands are located'. This means that states must also monitor the use of lands within their territories, and in addition they must have oversight over the processes of land acquisition. Badaru also refers to the Concluding Observations by the Committee on Economic, Social and Cultural Rights (ICESCR), in which the Committee has recommended the revision of investment law and to seek the free and informed consent of the persons concerned. She stresses this again by invoking Rezaie's suggestion for sanctions to be imposed on third parties when they start biofuel production on lands without having obtained prior informed consent (FPIC) from the stakeholders depending on those lands. ${ }^{14}$

FPIC is a clearly preventive obligation mentioned by both Budaru and de Tarso Lugon Arantes. In the context of the rights of indigenous peoples, the latter also refers to socio-environmental impact assessments and state-enforced land-demarcation as specific examples of preventive obligations. These could also be related to the context of food justice, which includes access to lands and natural resources and assumes cultural appropriateness.

Budaru also notes, in the context of food justice, that in case of violations a state must inquire what measures could have been put in place that would have prevented the third parties from causing violations of the right to food. In this assessment, the criterion of reasonableness plays a role. The state then has to put in place measures, including penalties, to deter others from causing similar violations of the right to food. In other words, this comes down to guarantees of non-repetition.

\footnotetext{
${ }^{13}$ HRCtee General Comment 31 on the General Legal Obligation Imposed on States Parties to the Covenant, CCPR/C/21/Rev1/Add,13, 29 March 2004, para. 8.

14 Rezaie (2017), pp. 155-195. For a general discussion of the right to participation in the context of economic, social and cultural rights, see Mosissa (2020), pp. 155-189. On participation and accountability for international organisations, see e.g. Schaap (2020).
} 
Moreover, Badaru argues, the obligation of international cooperation means that at the international level states must respect, protect and fulfil the right to food as well. Article 11 ICESCR pinpoints international cooperation as a relevant element to ensure the right to food. Hence, as she notes, states 'must refrain from taking actions that will negatively impact the realization of that right in other States'. This means concretely that when they set biofuel targets, states must consider the 'production opportunity costs - in terms of the negative impact on food production'and if necessary, states must reconsider these. Thus, states must respect the right in their international cooperation. In addition, in their international cooperation states must protect economic, social and cultural rights by taking measures to prevent nonstate entities under their jurisdiction from interfering with the enjoyment of these rights abroad.

The discussion of the use of the due diligence standard and the obligation of international cooperation is, in turn, relevant in the context of the discussion of the effectiveness of Human Rights Due Diligence (HRDD) for preventing human rights abuses by businesses, as examined by Justine Nolan and Robert McCorquodale in their contribution 'The Effectiveness of Human Rights Due Diligence for Preventing Business Human Rights Abuses'. In line with Ruggie's Guiding Principles on Business and Human Rights and the Protect, Respect and Remedy framework (2011), embraced by the UN, states have an international legal obligation to put in place effective methods to prevent actual and potential adverse human rights impacts and provide effective remedies to those affected'. States have the legal obligation to protect against actions by third parties (such as businesses), while businesses themselves have a responsibility to respect these rights. Guiding Principle 6.3 stipulates that those states shall require business enterprises to undertake human rights due diligence.

Nolan and McCorquodale note that this means that states should enact effective legislation to achieve this. They discuss how the key terms of the HRDD have been applied in domestic legislation and by courts, referring to interesting domestic cases confirming the duty of care of parent companies. They conclude that there is 'a strong momentum towards more national and regional legislation and mandatory HRDD, at least within parts of the Global North'. They then discuss 'the extent to which prevention through HRDD has pushed the development of new practices by states and businesses so as to improve responsiveness by them of dealing with adverse human rights impacts of business activities'. They note that HRDD is a 'coregulatory model', but that 'the state should assume the main preventative role so that the decision on compliance is not left to the discretion of business'. After all, the effectiveness research on HRDD and business so far shows that businesses generally have a 'very limited vision of HRDD' because they continue to rely on social auditing. This 'may result in cosmetic or self-legitimating compliance-oriented responses by business to address and reduce the potential for harms'. The authors stress that new laws and regulations mandating HRDD should not assume that mandating social audits would be sufficient, referring to 'a growing body of evidence' that social auditing on its own is 'an ineffective tool for achieving meaningful and consistent human rights improvements'. Instead, states should 'implement legislation requiring businesses to undertake HRDD that is both substantive and 
sustainable'. Like de Tarso Lugon Arantes, they stress that the focus should be on outcomes, not just process, and that the participation of the rights holders is key. For that, states should implement a mandatory HRDD 'that requires rights holders to be part of the corporate HRDD process'. HRDD should not serve as a risk management process legitimizing the actions of businesses without the participation of the rights holders. This means that there should be 'a state mandated enforcement framework that is adequately monitored and resourced that both incentivises business to act and penalises them if they do not, such as that offered in the UK Bribery Act'. Something similar would apply to early warning mechanisms, which should not only be transparent, but with clear involvement by the rights holders.

As also illustrated by Ferstman's contribution, a crucial hurdle that needs to be taken domestically as well as at the international level is setting up a system of structural monitoring. A system that includes generating data and submitting these to independent analysis by social scientists. It does not appear that at all levels of monitoring there is as yet a firm demand for states to provide disaggregated (and longitudinal) data to establish whether there has been an increase or decrease in violations, accompanied by data on possible explanatory factors. This should consistently include information on what measures a state takes to respect privacy and prevent bias in general in the manner in which it harvests and interprets data, and in how third parties do so. ${ }^{15}$

\section{Expert Documents Identifying Preventive Obligations of States}

As noted by Diana Odier-Contreras, reparations for gross human rights violations, whenever possible, 'should seek not only to address suffering, but also to address the structural problems that led to this suffering'. Therefore, 'collective reparations should aim at meeting victims' needs while transforming conditions that may lead to further [such violations]. In other words, they should adopt a preventive approach based on transforming structural problems'. ${ }^{16}$

The UN Human Rights Council has established a Special Rapporteur on the promotion of truth, justice, reparation \& guarantees of non-recurrence. This demonstrates its awareness of the relationship between prevention and redress, and the importance of truth for both. Many measures recommended by this Rapporteur are aimed at preventing further violations: legislative reform; institutional reform, such as strengthening judicial independence; establishing civilian oversight over security forces; making changes in policing strategies; educational reform (including ensuring that history teaching is inclusive and reconciliatory); including contributions by civil society organizations and other influential local actors such as religious leaders,

\footnotetext{
15 See e.g. CERD General Recommendation No. 36 (2020) on preventing and combating racial profiling by law enforcement officials, CERD/C/GC/36, 17 December 2020, especially the recommendations in paras. 50, 51 and 58-69; European Commission against Racism and Intolerance (ECRI), General Policy recommendation on combatting racial discrimination in employment, 22 June 2012, 10a; Frederik Zuiderveen Borgesius, 'Discrimination, artificial intelligence and algorithmic decision-making', Directorate General of Democracy, Council of Europe-2018.

16 Odier-Contreras Garduna (2019), p. 324.
} 
labour or professional organisations; and recommending a combination of remedies: a comprehensive and integral approach, adapted to the situation, inclusive, participatory, and with local ownership. ${ }^{17}$ The Rapporteur has also recently discussed established democracies having to deal with a violent (not so distant) past. ${ }^{18}$ An official public acknowledgment of the facts can play a role not only in redress, but also in preventing further violations.

As shown in the contributions in this issue, the preventive obligations of states include their extraterritorial obligations. The Maastricht Principles on Extraterritorial Obligations of States in the Area of Economic, Social and Cultural Rights (ETO principles, 2011) ${ }^{19}$ refer to the circumstances in which states have the obligation to act, being in a position to regulate conduct by entities and individuals in their activities abroad, as well as to the obligation of states to use their position of influence, and their obligation to cooperate. ${ }^{20}$ This cooperation is specified further in the obligations to fulfil. ${ }^{21}$ It is useful to reproduce ETO Principle 32 in full:

In fulfilling economic, social and cultural rights extraterritorially, States must:

a) prioritize the realisation of the rights of disadvantaged, marginalized and vulnerable groups;

b) prioritize core obligations to realize minimum essential levels of economic, social and cultural rights, and move as expeditiously and effectively as possible towards the full realization of economic, social and cultural rights;

c) observe international human rights standards, including the right to self-determination and the right to participate in decision-making, as well as the principles of non-discrimination and equality, including gender equality, transparency, and accountability; and

d) avoid any retrogressive measures or else discharge their burden to demonstrate that such measures are duly justified by reference to the full range of human rights

\footnotetext{
17 See e.g. the respective reports of UN Special Rapporteurs on the promotion of truth, justice, reparation \& guarantees of non-recurrence, Pablo de Greiff, A comprehensive framework of prevention, A/72/523, October 2017, and of Fabián Salvioli, e.g. A/HRC/39/53, 25 July 2018. See also the Special Rapporteur on the promotion of truth, justice, reparation and guarantees of non-recurrence and the Special Adviser to the Secretary-General on the Prevention of Genocide, Joint study on the contribution of transitional justice to the prevention of gross violations and abuses of human rights and serious violations of international humanitarian law, including genocide, war crimes, ethnic cleansing and crimes against humanity, and their recurrence, A/HRC/37/65, 6 June 2018.

18 UN Special Rapporteur on the promotion of truth, justice, reparation and guarantees of non-recurrence, Fabián Salvioli, Transitional justice measures and addressing the legacy of gross violations of human rights and international humanitarian law committed in colonial contexts, A/76/180, 19 July 2021.

19 Maastricht Principles on Extraterritorial Obligations of States in the Area of Economic, Social and Cultural Rights (ETO Principles, 2011). Principles 1-3 refer to the indivisibility between economic, social, cultural, civil and political rights and their integral protection. The ETO Principles can be found at: https://www.etoconsortium.org/nc/en/main-navigation/library/maastricht-principles/?tx_drblob_pi1\% 5BdownloadUid\%5D=23. Accessed 3 December 2022.

20 ETO Principles 23-27.

21 Ibid., 28-35.
} 
obligations, and are only taken after a comprehensive examination of alternatives. $^{22}$

The year 2021 saw several expert-led initiatives that assist in clarifying preventive obligations in the field of human rights and the roles of various actors in this. Regarding the prevention of torture and cruel treatment this includes the important Méndez Principles on Effective Interviewing for Investigations and Information Gathering, which clearly identify a range of measures that must be taken by law enforcement officers to gather information and conduct interviews in a manner that prevents torture and cruel treatment. ${ }^{23}$

With regard to the preventive obligations of states pending international proceedings, the Nijmegen Principles and Guidelines on Interim Measures for the Protection of Human Rights (2021) zoom in specifically on the obligations of states, on the one hand, and good institutional, lawyering and judicial practices with regard to interim measures, on the other. ${ }^{24}$ There are urgent preventive obligations that must be implemented immediately because of the immediacy of the impending harm, and others that must be implemented more gradually through a range of measures. Also, in the face of requests for interim measures, a structural situation can be taken into account. As Rosa Möhrlein and I noted in this regard, in all human rights systems adjudicators (courts and quasi-judicial bodies) are asked to respond to individual or collective requests for interim measures also in the context of structural violations. ${ }^{25}$ This is why Article $1 \mathrm{~g}$ of the Nijmegen Principles notes that in such contexts 'States are obliged to investigate and report on such violations, or allow and facilitate fact-finding missions to help prevent new violations or halt their continuation.' It observes that this obligation also applies pending international adjudication and 'the relevant international adjudicator may remind States of this through interim measures or other urgent measures'. Obviously, it is particularly difficult to achieve immediate compliance with interim measures in the context of structural violations. $^{26}$

Nevertheless, in the Inter-American system, the Commission and Court do show an awareness of structural contexts also when they order provisional or precautionary measures. Drawing inspiration from the Inter-American system, the following guidelines in the Nijmegen Principles stress the importance of creative, specific and situation-responsive interim measures: Guideline 3(a) ('or in response to credible information of structurally urgent situations involving a class or group of persons');

\footnotetext{
${ }^{22}$ For an in-depth discussion, including of the nature and status of 'international cooperation', see Pijnenburg (2021). Another recent study on establishing responsibility and its importance for helping prevent adverse human rights impacts is Heerdt (2021).

23 See: Méndez Principles on Effective Interviewing for Investigations and Information Gathering (2021), https://www.apt.ch/en/resources/publications/new-principles-effective-interviewing-investigat ions-and-information. Accessed 3 December 2022.

24 Nijmegen Principles and Guidelines on Interim Measures for the Protection of Human Rights (2021), https://www.ru.n1/law/ster/research/nijmegen-principles-and-guidelines-on-interim/. Accessed 3 December 2022 .

25 Rieter and Möhrlein (2021).

${ }^{26}$ See further Rieter and Zwaan (2021).
} 
3(o) ('Yet urgent measures may also seek to safeguard against irreparable harm to other rights, or to safeguard parties beyond the scope of a specific complaint, especially in the context of structural, systematic, or widespread human rights violations and in the face of irreversible risks to the rule of law.'); 3(p) ('The measures ordered should be responsive to the alleged situation of the victims, and sufficiently specific about what the States are expected to do. They should show sensitivity to structural contexts and to persons in situations of particular vulnerability'); and 3(q) ('In the face of societal controversy or indifference, or in the face of State security abuses or armed conflict, there is a heightened need for creative and situation-specific approaches by international adjudicators. These approaches may include precisely formulated interim measures, especially aimed at preserving and securing evidence (including facilitating an international fact-finding mission), or aimed at the provision of urgent access to humanitarian aid').

An interesting example of an interim measure reflecting several preventive obligations discussed in this issue is the Inter-American Commission's 'precautionary measure' of January 2021 on behalf of Members of the Guajajara and Awá Indigenous Peoples of the Araribóia Indigenous Land, living in voluntary isolation. Reflecting the pre-eminence of the wishes of the rights holders, cultural appropriateness, the interdependence of rights (e.g. health, life, dignity, cultural survival), and of course the need for investigation and follow-up, the Commission called upon Brazil to:

(a) adopt the necessary measures to protect the rights to health, life, and personal integrity of the members of the Guajajara and Awá Indigenous Peoples of the Araribóia Indigenous Land, while implementing, from a culturally appropriate perspective, preventive measures against the spread of COVID-19, and providing them with adequate medical care in conditions of availability, accessibility, acceptability, and quality, in accordance with applicable international standards;

(b) agree on the measures to be adopted with the beneficiaries and their representatives; and

(c) report on the actions implemented to investigate the incidents that led to the adoption of this precautionary measure so as to prevent such incidents from reoccurring. ${ }^{27}$

Death threats and harassment against human rights defenders are particularly pernicious human rights violations, and they often occur in a context of structural violations. Most human rights adjudicators have tried to grapple with these violations. ${ }^{28}$ On the preventive obligations of states specifically with regard to the protection of human rights defenders, in 2021 another expert-led initiative led to the Esperanza Protocol, ${ }^{29}$ discussing, among other things, the range of the human rights at stake, specific due diligence obligations, as well as general due diligence 'and

\footnotetext{
27 IAComHR, Resolution No. 1/21 PM 754-20-Members of the Guajajara and Awá Indigenous Peoples of the Araribóia Indigenous Land, Brazil, 4 January 2022.

28 For early examples see Rieter (2010), pp. 405-449.

29 Centre for Justice and International law (CEJIL), Esperanza Protocol, An effective response to threats against human rights defenders, 2021, at https://esperanzaprotocol.net/. Accessed 3 December 2022.
} 
the obligation to create a safe and enabling environment to defend rights free from threats and other forms of violence'. Many of the criteria and guidelines included appear to be also relevant for preventive obligations in other (human rights) contexts.

\section{Benchmarks for Preventive Human Rights Obligations}

The obligation to prevent human rights violations, including those qualified as structural, is both intuitively obvious and practically complicated and a continuous discussion is warranted, among a range of experts, from various perspectives. Some measures are required by way of redress to victims but are also obligations to address structural problems in order to prevent further violations. The right to truth and the obligation to investigate and prosecute, for instance, may not only be reactive but also preventive, in terms of guarantees of non-repetition. The UN Special Rapporteur dealing with truth, justice, reparation and guarantees of non-recurrence should be able to shed further light on this.

At the same time, it should be kept in mind that there are risks attached to the prevention argument. Preventive measures in response to armed conflict, environmental disasters, epidemics, etc. may have a disproportionate impact on marginalized people. This is because states may take measures limiting rights, or derogating from them, in the name of prevention. Or dominant segments of society may take measures in a futile attempt to avoid all risks. It is therefore important to explore further what can be done to prevent repression in the name of prevention.

To stimulate further discussion of the preventive obligations of states, in particular to prevent structural violations, here are five recommendations, largely drawn from the ensuing contributions:

1. To achieve a better understanding of systemic issues and how states and others can meet their preventive human rights obligations they need to draw from a range of legal and non-legal disciplines.

2. In the context of judicial proceedings, states must respect interim measures and thereby ensure that pending the proceedings no irreparable harm is caused to persons or groups by its agents or third parties, nor to the integrity of the proceedings. These are clear preventive obligations. Moreover, in the face of patterns of violations states must take measures that address systemic underlying issues and ensure that all similarly situated persons are protected collectively, and that collective preventive remedies are provided. States must take a comprehensive, integral approach to human rights and their obligations to respect, protect and fulfil economic, social, cultural, civil and political rights, group rights and individual rights. This also applies to their obligation to do so by taking preventive measures. These obviously relate to the obligation to protect, but the obligations to respect and fulfil are triggered as well. After all, the rights are interrelated and interdependent and the various necessary acts and omissions are sometimes required immediately, sometimes simultaneously and at other times consecutively.

3. States must base their preventive actions on the insights and wishes of the groups of rights holders affected; this includes the obligation to (a) provide information to the rights holders; (b) consult them; (c) facilitate participation, especially of 
marginalised groups (who must be recognised as themselves being agents of change); (d) ensure that decisions regarding the state's expropriating land for public building, extraction and infrastructure, and its investment and-granting rights to-business developments, are based on Free, Prior and Informed Consent. These obligations are primary rules on prevention, as well as secondary rules on substantive remedies that are in fact aimed at prevention. The latter means that these rules also apply to specific measures that will be taken to avoid a recurrence of violations (guarantees of non-repetition).

4. States must collect and provide aggregated data to allow independent monitoring bodies to assess how well they meet their international preventive obligations in the face of structural problems such as domestic abuse and racial discrimination, both by private parties and by public officials. They must also not provide ethnic background data for domestic (tax) law enforcement and the creation of risk profiles, and must avoid invoking the obligation to prevent crime as a justification for repression. A good example of what is required for the preventive obligation to collect, interpret and act upon data, and safeguards against abuses of data, can be found in the Esperanza Protocol (2021) on the protection of human rights defenders. ${ }^{30}$

5. To avoid situations in which states, international organisations, and businesses can conveniently escape scrutiny simply by ticking boxes, outcome or actual practice should be at least as important as process to determine whether preventive obligations have been met. Independent monitoring must be performed through strict scrutiny of the facts based on the substantive law.

Acknowledgements The author would like to thank Anna Meijknecht and Menno Kamminga for their valuable suggestions.

\section{References}

Boersma M (2012) Corruption: a violation of human rights and a crime under international law? Intersentia, Antwerp

De Schutter O, Ringelheim J (2010) Ethnic monitoring: the processing of racial and ethnic data in anti-discrimination policies: reconciling the promotion of equality with privacy rights. Bruylant, Brussels

Figueiredo ATD (2017) Corruption and human rights, beyond the link. Wolf Legal Publishers, Nijmegen

Heerdt D (2021) Blurred lines of responsibility and accountability, human rights abuses at mega-sporting events. Intersentia, Antwerp

Makkonen T (2012) Equal in law, unequal in fact-racial and ethnic discrimination and the legal response thereto in Europe. Martinus Nijhoff Publishers, Leiden

Mosissa GA (2020) A re-examination of economic, social and cultural rights in a political society in the light of the principle of human dignity. Intersentia, Antwerp, pp 155-189

Muigua K (2019) Maximising the right to free, prior, and informed consent for enhanced environmental justice in Kenya. Available at: https://thelawyer.africa/2021/11/17/free-prior-and-informed-consent. Accessed 27 Nov 2021

30 Esperanza Protocol, para. VI a, pp. 22-24. 
Odier-Contreras Garduna D (2019) Collective reparations, tensions and dilemma's between collective reparations with the individual right to receive reparations. Intersentia, Antwerp

Peters A (2018) Corruption as a violation of international human rights. Eur J Int Law EJIL 29(4):1251-1287

Pijnenburg A (2021) At the frontiers of state responsibility, socio-economic rights and cooperation on migration. Intersentia, Antwerp

Rezaie AH (2017) Upholding the human right to food in the face of agro-biofuel technology. Can J Hum Rights 6:155-195

Rieter (2010) Preventing irreparable harm, provisional measures in international human rights adjudication. Intersentia, Antwerp

Rieter E, Möhrlein R (2021) The Nijmegen principles and guidelines on interim measures. Maintaining and enhancing the protective potential of interim measures in human rights cases. https://voelkerrec htsblog.org/the-nijmegen-principles-and-guidelines-on-interim-measures-2021/. Accessed 19 Jul 2021

Rieter E, Zwaan K (eds) (2021) Urgency and human rights, the protective potential and legitimacy of interim measures. TMC Asser Press, The Hague

Rose C (2015) International anti-corruption norms: their creation and influence on domestic legal systems. OUP, Oxford

Schaap M (2020) An inclusionary governance model for international institutions, ensuring accountability towards individuals (diss), Erasmus University Rotterdam

Wouters J, Ryngaert C, Cloots AS (2013) The international legal framework against corruption: achievements and challenges. Melb J Int Law 14:209

Publisher's Note Springer Nature remains neutral with regard to jurisdictional claims in published maps and institutional affiliations. 